\title{
From Knowledge to Wisdom: The Need for an Academic Revolution

\author{
Nicholas Maxwell
} \\ (Emeritus Reader and Honorary Senior Research Fellow at University College London)
}

(Published in R. Barnett and N. Maxwell, eds., Wisdom in the University, Routledge 2008. See also London Review of Education, 5, 2007, pp. 97-115.)

Things fall apart; the centre cannot hold; Mere anarchy is loosed upon the world, The blood-dimmed tide is loosed, and everywhere

The ceremony of innocence is drowned; The best lack all conviction, while the worst Are full of passionate intensity.

\begin{abstract}
At present the basic intellectual aim of academic inquiry is to improve knowledge. Much of the structure, the whole character, of academic inquiry, in universities all over the world, is shaped by the adoption of this as the basic intellectual aim. But, judged from the standpoint of making a contribution to human welfare, academic inquiry of this type is damagingly irrational. Three of four of the most elementary rules of rational problemsolving are violated. A revolution in the aims and methods of academic inquiry is needed so that the basic aim becomes to promote wisdom, conceived of as the capacity to realize what is of value, for oneself and others, thus including knowledge and technological know-how, but much else besides. This urgently needed revolution would affect every branch and aspect of the academic enterprise.
\end{abstract}

\section{Introduction}

The world today is beset with problems. Most serious of all, perhaps, there is the impending problem of global warming. There is the problem of the progressive destruction of tropical rain forests and other natural habitats, with its concomitant devastating extinction of species. There is the problem of war, over 100 million people having died in countless wars in the 20th century (which compares unfavourably with the 12 million or so killed in wars during the 19th century). There is the arms trade, the massive stockpiling of armaments, even by poor countries, and the ever-present threat of their use by terrorists or in war, whether the arms be conventional, chemical, biological or nuclear. There is the sustained and profound injustice of immense differences of wealth across the globe, the industrially advanced first world of North America, Europe and elsewhere experiencing unprecedented wealth while something like a third of humanity live in conditions of poverty in the developing world, hungry, unemployed, without proper housing, health care, education, or even access to safe water. There is the long-standing problem of the rapid growth of the world's population, especially pronounced in the poorest parts of the world, and adversely affecting efforts at development. And there is the horror of the AIDS epidemic, again far more terrible in 
the poorest parts of the world, devastating millions of lives, destroying families, and crippling economies.

And, in addition to these stark global crises, there are problems of a more diffuse, intangible character, signs of a general cultural or spiritual malaise. There is the phenomenon of political apathy: the problems of humanity seem so immense, so remorseless, so utterly beyond human control, and each one of us, a mere individual, seems wholly impotent before the juggernaut of history. The new global economy can seem like a monster out of control, with human beings having to adapt their lives to its demands, rather than gaining support from it. There is the phenomenon of the trivialization of culture, as a result, perhaps, of technological innovation such as TV and the internet. Once, people created and participated in their own live music, theatre, art, poetry. Now this is pumped into our homes and into our ears by our technology, a massproduced culture for mass consumption; we have become passive consumers, and the product becomes ever more trivial in content. And finally, there is the phenomenon of the rise of religious and political fanaticism and terrorism opposed, it can seem, either in a faint-hearted and self-doubting way, or brutally by war and the suspension of justice, apparently confirming Yeats's lines "The best lack all conviction, while the worst are full of passionate intensity".

\section{From Knowledge to Wisdom}

What can be done in response to global problems such as these? There are a multitude of things that can be done, and are being done, in varying degrees, with varying amounts of success. Here, I wish to concentrate on just one thing that could be done, which would go to the heart of the above global problems, and to the heart of our apparent current incapacity to respond adequately to these problems.

We need to bring about a wholesale, structural revolution in the aims and methods, the entire intellectual and institutional character of academic inquiry. At present academic inquiry is devoted to acquiring knowledge. The idea is to acquire knowledge, and then apply it to help solve social problems. This needs to change, so that the basic aim becomes to seek and promote wisdom - wisdom being understood to be the capacity to realize what is of value in life for oneself and others (and thus including knowledge, know-how and understanding). Instead of devoting itself primarily to solving problems of knowledge, academic inquiry needs to give intellectual priority to the task of discovering possible solutions to problems of living.

The social sciences need to become social philosophy, or social methodology, devoted to promoting more cooperatively rational solving of conflicts and problems of living in the world. Social inquiry, so pursued, would be intellectually more fundamental than natural science. The natural sciences need to recognize three domains of discussion: evidence, theories, and aims. Problems concerning research aims need to be discussed by both scientists and non-scientists alike, involving as they do questions concerning social priorities and values. Philosophy needs to become the sustained rational exploration of our most fundamental problems of understanding; it also needs to take up the task of discovering how we may improve our personal, institutional and global aims and methods in life, so that what is of value in life may be realized more successfully. Education needs to change so that problems of living become more fundamental than problems of knowledge, the basic aim of education being to learn how to acquire wisdom 
in life. Academic inquiry as a whole needs to become somewhat like a people's civil service, having just sufficient power to retain its independence and integrity, doing for people, openly, what civil services are supposed to do, in secret, for governments. These and many other changes, affecting every branch and aspect of academic inquiry, all result from replacing the aim to acquire knowledge by the aim to promote wisdom by cooperatively rational means. (see Maxwell, N., 1976, 1984, 2004).

\section{The Crisis of Science without Wisdom}

It may seem surprising that I should suggest that changing the aims and methods of academic inquiry would help us tackle the above global problems. It is, however, of decisive importance to appreciate that all the above global problems have arisen because of a massive increase in scientific knowledge and technology without a concomitant increase in global wisdom. Degradation of the environment due to industrialization and modern agriculture, global warming, the horrific number of people killed in war, the arms trade and the stockpiling of modern armaments, the immense differences in the wealth of populations across the globe, rapid population growth: all these have been made possible by the rapid growth of science and technology since the birth of modern science in the 17th century. Modern science and technology are even implicated in the rapid spread of AIDS in the last few decades. It is possible that, in Africa, AIDS has been spread in part by contaminated needles used in inoculation programmes; and globally, AIDS has spread so rapidly because of travel made possible by modern technology. And the more intangible global problems indicated above may also have come about, in part, as a result of the rapid growth of modern science and technology.

That the rapid growth of scientific knowledge and technological know-how should have these kinds of consequence is all but inevitable. Scientific and technological progress massively increase our power to act: in the absence of wisdom, this will have beneficial consequences, but will also have harmful ones, whether intended, as in war, or unforeseen and unintended (initially at least), as in environmental degradation. As long as we lacked modern science, lack of wisdom did not matter too much: our power to wreak havoc on the planet and each other was limited. Now that our power to act has been so massively enhanced by modern science and technology, global wisdom has become, not a luxury, but a necessity.

The crisis of our times, in short - the crisis behind all the others - is the crisis of science without wisdom. Having a kind of academic inquiry that is, by and large, restricted to acquiring knowledge can only serve to intensify this crisis. Changing the nature of science, and of academic inquiry more generally, is the key intellectual and institutional change that we need to make in order to come to grips with our global problems - above all, the global problem behind all the others, the crisis of everincreasing technological power in the absence of wisdom. We urgently need a new kind of academic inquiry that gives intellectual priority to promoting the growth of global wisdom.

\section{The Damaging Irrationality of Knowledge-Inquiry}

There are those who simply blame scientific rationality for our problems. Scientific rationality needs to be restrained, it is argued, by intuition and tradition, by morality or religion, by socialism, or by insights acquired from the arts or humanities: (see Marcuse, 
1964; Laing, 1965; Roszak, 1973; Berman, 1981; Schwartz, 1987; Feyerabend, 1978, 1987; Appleyard, 1992). But this kind of response profoundly misses the point. What we are suffering from is not too much reason, but not enough. Scientific rationality, socalled, is actually a species of damaging irrationality masquerading as rationality. Academic inquiry as it mostly exists at present, devoted to the growth of knowledge and technological know-how - knowledge-inquiry I shall call it (Maxwell, 1984, chapters 2 and 6) - is actually profoundly irrational when judged from the standpoint of contributing to human welfare. Judged from this all-important standpoint, knowledge-inquiry violates three of the four most elementary, uncontroversial rules of reason that one can conceive of (to be indicated in a moment). And that knowledge-inquiry is grossly irrational in this way has everything to do with its tendency to generate the kind of global problems considered above. Instead of false simulacra of reason, what we so urgently need is authentic reason devoted to the growth of wisdom.

Knowledge-inquiry demands that a sharp split be made between the social or humanitarian aims of inquiry and the intellectual aim. The intellectual aim is to acquire knowledge of truth, nothing being presupposed about the truth. Only those considerations may enter into the intellectual domain of inquiry relevant to the determination of truth - claims to knowledge, results of observation and experiment, arguments designed to establish truth or falsity. Feelings and desires, values, ideals, political and religious views, expressions of hopes and fears, cries of pain, articulation of problems of living: all these must be ruthlessly excluded from the intellectual domain of inquiry as having no relevance to the pursuit of knowledge - although of course inquiry can seek to develop factual knowledge about these things, within psychology, sociology or anthropology. Within natural science, an even more severe censorship system operates: an idea, in order to enter into the intellectual domain of science, must be an empirically testable claim to factual knowledge.

The basic idea of knowledge-inquiry, then, is this. First, knowledge is to be acquired; then it can be applied to help solve social problems. For this to work, authentic objective knowledge must be acquired. Almost paradoxically, human values and aspirations must be excluded from the intellectual domain of inquiry so that genuine factual knowledge is acquired and inquiry can be of genuine human value, and can be capable of helping us realize our human aspirations. ${ }^{1}$

This is the conception of inquiry which, I claim, violates reason in a wholesale, structural and damaging manner.

But what do I mean by "reason"? As I use the term here, rationality appeals to the idea that there are general methods, rules or strategies which, if put into practice, give us our best chance, other things being equal, of solving our problems, realizing our aims. Rationality is an aid to success, but does not guarantee success, and does not determine what needs to be done.

Four elementary rules of reason, alluded to above, are:

\footnotetext{
${ }^{1}$ For a much more detailed exposition of knowledge-inquiry, or "the philosophy of knowledge", see Maxwell (1984, chapter 2). For evidence that knowledge-inquiry prevails in academia, see Maxwell (1984, chapter $6 ; 2000 ; 2007$, chapter 6$)$. I do not claim that everything in academia accords with the edicts of knowledge-inquiry. My claim is, rather, that this is the only candidate for rational inquiry in the public arena; it is the dominant view, exercising an all-pervasive influence over academe. Work that does not conform to its edicts has to struggle to survive.
} 
(1) Articulate and seek to improve the articulation of the basic problem(s) to be solved.

(2) Propose and critically assess alternative possible solutions.

(3) When necessary, break up the basic problem to be solved into a number of specialized problems - preliminary, simpler, analogous, subordinate problems - (to be tackled in accordance with rules (1) and (2)), in an attempt to work gradually toward a solution to the basic problem to be solved.

(4) Inter-connect attempts to solve the basic problem and specialized problems, so that basic problem solving may guide, and be guided by, specialized problem solving.

No enterprise which persistently violates (1) to (4) can be judged rational. If academic inquiry is to contribute to the aim of promoting human welfare, the quality of human life, by intellectual means, in a rational way, in a way that gives the best chances of success, then (1) to (4) must be built into the whole institutional/intellectual structure of academic inquiry.

In order to see that current academic inquiry, devoted primarily to the pursuit of knowledge, does indeed violate three of the above four rules of reason (when viewed from the standpoint of contributing to human welfare), two preliminary points need to be noted about the nature of the problems that academic inquiry ought to be trying to help solve.

First, granted that academic inquiry has, as its fundamental aim, to help promote human welfare by intellectual and educational means, ${ }^{2}$ then the problems that inquiry fundamentally ought to try to help solve are problems of living, problems of action. From the standpoint of achieving what is of value in life, it is what we do, or refrain from doing, that ultimately matters. Even where new knowledge and technological know-how are relevant to the achievement of what is of value - as it is in medicine or agriculture, for example - it is always what this new knowledge or technological know-how enables us to do that matters. All the global problems discussed above require, for their resolution, not merely new knowledge, but rather new policies, new institutions, new ways of living. Scientific knowledge, and associated technological know-how have, if anything, as we have seen, contributed to the creation of these problems in the first place. Thus problems of living - problems of poverty, ill-health, injustice, deprivation - are solved by what we do, or refrain from doing; they are not solved by the mere provision of some item of knowledge (except when a problem of living is a problem of knowledge).

\footnotetext{
${ }^{2}$ This assumption may be challenged. Does not academic inquiry seek knowledge for its own sake - it may be asked - whether it helps promote human welfare or not? Later on, I will argue that the conception of inquiry I am arguing for, wisdom-inquiry, does better justice than knowledge-inquiry to both aspects of inquiry, pure and applied. The basic aim of inquiry, according to wisdom-inquiry, is to help us realize what is of value in life, "realize" meaning both "apprehend" and "make real". "Realize" thus accommodates both aspects of inquiry, "pure" research or "knowledge pursued for its own sake" on the one hand, and technological or "mission-oriented" research on the other - both, ideally, seeking to contribute to what is of value in human life. Wisdom-inquiry, like sight, is there to help us find our way around. And like sight, wisdom-inquiry is of value to us in two ways: for its intrinsic value, and for practical purposes. The first is almost more precious than the second.
} 
Second, in order to achieve what is of value in life more successfully than we do at present, we need to discover how to resolve conflicts and problems of living in more cooperatively rational ways than we do at present. There is a spectrum of ways in which conflicts can be resolved, from murder or all out war at the violent end of the spectrum, via enslavement, threat of murder or war, threats of a less extreme kind, manipulation, bargaining, voting, to cooperative rationality at the other end of the spectrum, those involved seeking, by rational means, to arrive at that course of action which does the best justice to the interests of all those involved. A basic task for a kind of academic inquiry that seeks to help promote human welfare must be to discover how conflict resolution can be moved away from the violent end of the spectrum towards the cooperatively rational end.

Granted all this, and granted that the above four rules of reason are put into practice then, at the most fundamental level, academic inquiry needs to:

(1) Articulate, and seek to improve the articulation of, personal, social and global problems of living that need to be solved if the quality of human life is to be enhanced (including those indicated above);

(2) Propose and critically assess alternative possible solutions - alternative possible actions, policies, political programmes, legislative proposals, ideologies, philosophies of life.

In addition, of course, academic inquiry must:

(3) Break up the basic problems of living into subordinate, specialized problems - in particular, specialized problems of knowledge and technology.

(4) Inter-connect basic and specialized problem solving.

Academic inquiry as it mostly exists at present can be regarded as putting (3) into practice to splendid effect. The intricate maze of specialized disciplines devoted to improving knowledge and technological know-how that go to make up current academic inquiry is the result. But, disastrously, what we have at present, academic inquiry devoted primarily to improving knowledge, fails to put (1), (2) and (4) into practice. In pursuing knowledge, academic inquiry may articulate problems of knowledge, and propose and critically assess possible solutions, possible claims to knowledge - factual theses, observational and experimental results, theories. But, as we have seen, problems of knowledge are not (in general) problems of living; and solutions to problems of knowledge are not (in general) solutions to problems of living. Insofar as academia does at present put (1) and (2) into practice, in departments of social science and policy studies, it does so only at the periphery, and not as its central, fundamental intellectual task.

In short, academic inquiry devoted primarily to the pursuit of knowledge, when construed as having the basic humanitarian aim of helping to enhance the quality of human life by intellectual means, fails to put the two most elementary rules of reason into practice (rules (1) and (2)). Academic inquiry fails to do (at a fundamental level) what it most needs to do, namely (1) articulate problems of living, and (2) propose and critically assess possible solutions. And furthermore, as a result of failing to explore the basic 
problems that need to be solved, academic inquiry cannot put the fourth rule of rational problem solving into practice either, namely (4) inter-connect basic and specialized problem solving. As I have remarked, three of the four most elementary rules of rational problem solving are violated. (For a more detailed development of this argument see Maxwell, 1980, 1984, 2004.)

This gross structural irrationality of contemporary academic inquiry, of knowledgeinquiry, is no mere formal matter. It has profoundly damaging consequences for humanity. As I have pointed out above, granted that our aim is to contribute to human welfare by intellectual means, the basic problems we need to discover how to solve are problems of living, problems of action, not problems of knowledge. In failing to give intellectual priority to problems of living, knowledge-inquiry fails to tackle what most needs to be tackled in order to contribute to human welfare. In devoting itself to acquiring knowledge in a way that is unrelated to sustained concern about what humanity's most urgent problems are, as a result of failing to put (1) and (2) into practice, and thus failing to put (4) into practice as well, the danger is that scientific and technological research will respond to the interests of the powerful and the wealthy, rather than to the interests of the poor, of those most in need. Scientists, officially seeking knowledge of truth per se, have no official grounds for objecting if those who fund research - governments and industry - decide that the truth to be sought will reflect their interests, rather than the interests of the world's poor. And priorities of scientific research, globally, do indeed reflect the interests of the first world, rather than those of the third world. ${ }^{3}$

Knowledge and technology successfully pursued in a way that is not rationally subordinated to the tackling of more fundamental problems of living, through the failure to put (1), (2) and (4) into practice, is bound to lead to the kind of global problems discussed above, problems that arise as a result of newly acquired powers to act being divorced from the ability to act wisely. The creation of our current global problems, and our inability to respond adequately to these problems, has much to do, in other words, with the long-standing, rarely noticed, structural irrationality of our institutions and traditions of learning, devoted as they are to acquiring knowledge dissociated from learning how to tackle our problems of living in more cooperatively rational ways. Knowledge-inquiry, because of its irrationality, is designed to intensify, not help solve, our current global problems. ${ }^{4}$

\section{Wisdom-Inquiry}

Inquiry devoted primarily to the pursuit of knowledge is, then, grossly and damagingly irrational when judged from the standpoint of contributing to human welfare by intellectual means. At once the question arises: What would a kind of inquiry be like that is devoted, in a genuinely rational way, to promoting human welfare by intellectual means? I shall call such a hypothetical kind of inquiry wisdom-inquiry, to stand in contrast to knowledge-inquiry.

\footnotetext{
${ }^{3}$ Funds devoted, in the USA, UK and some other wealthy countries, to military research are especially disturbing: see Langley (2005) and Smith (2003).

${ }^{4}$ See Maxwell (1984, chapter 3 ) for a much more detailed discussion of the damaging social repercussions of knowledge-inquiry.
} 
As a first step at characterizing wisdom-inquiry, we may take knowledge-inquiry (at its best) and modify it just sufficiently to ensure that all four elementary rules of rational problem-solving, indicated above, are built into its intellectual and institutional structure: see Figure 1.

The primary change that needs to be made is to ensure that academic inquiry implements rules (1) and (2). It becomes the fundamental task of social inquiry and the humanities (1) to articulate, and seek to improve the articulation of, our problems of living, and (2) to propose and critically assess possible solutions, from the standpoint of their practicality and desirability. In particular, social inquiry has the task of discovering how conflicts may be resolved in less violent, more cooperatively rational ways. It also

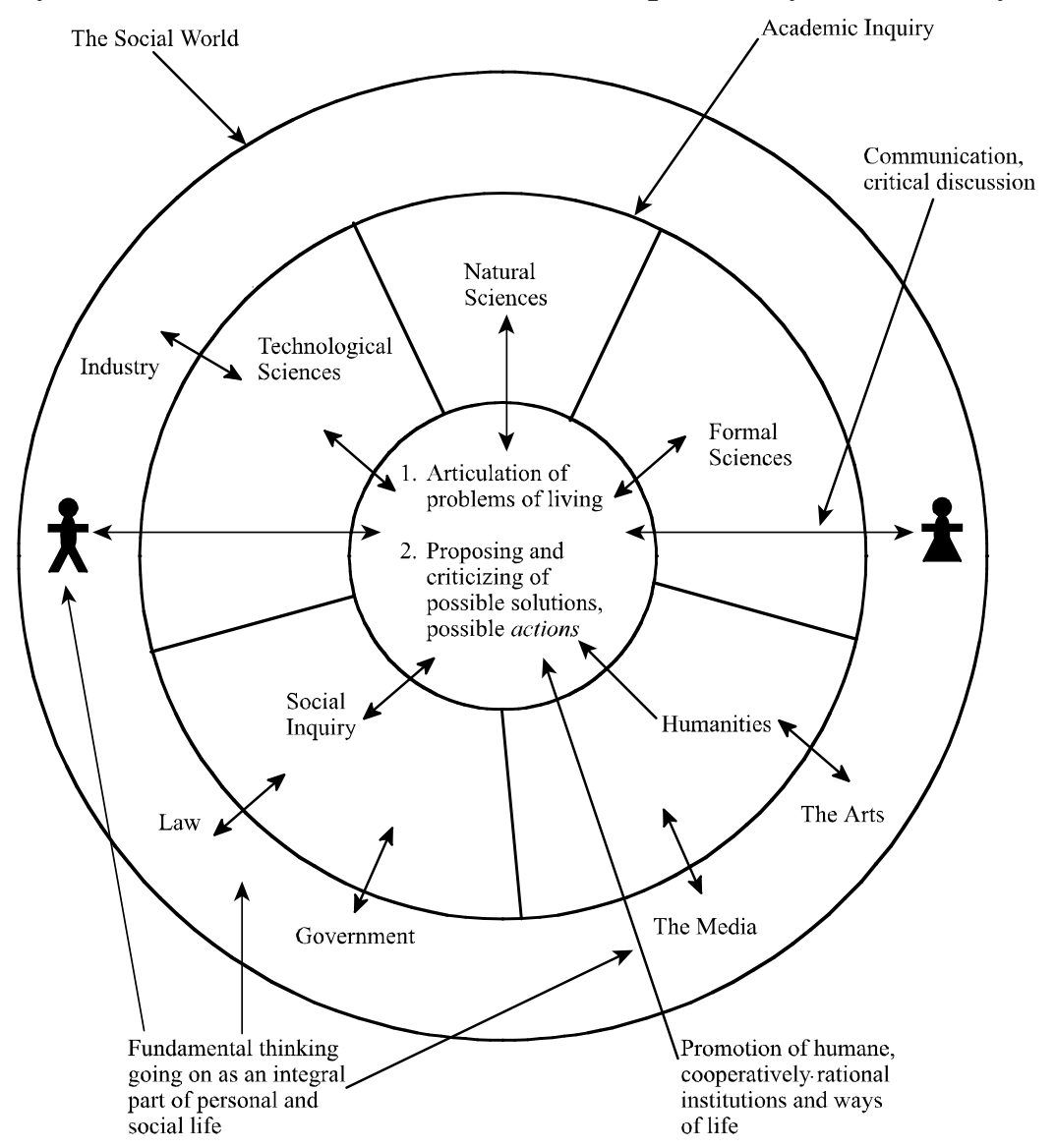

Figure 1: Wisdom-Inquiry Implementing Problem-Solving Rationality (Please enlarge to view)

has the task of promoting such tackling of problems of living in the social world beyond academe. Social inquiry is, thus, not primarily social science, nor, primarily, concerned to acquire knowledge of the social world; its primary task is to promote more cooperatively rational tackling of problems of living in the social world. Pursued in this way, social inquiry is intellectually more fundamental than the natural and technological sciences, which tackle subordinate problems of knowledge, understanding and technology, in accordance with rule (3). In Figure 1, implementation of rule (3) is 
represented by the specialized problem solving of the natural, technological and formal sciences, and more specialized aspects of social inquiry and the humanities. Rule (4) is represented by the two-way arrows linking fundamental and specialized problem solving, each influencing the other.

One can go further. According to this view, the thinking that we engage in as we live, in seeking to realize what is of value to us, is intellectually more fundamental than the whole of academic inquiry (which has, as its basic purpose, to help cooperatively rational thinking and problem solving in life to flourish). Academic thought emerges as a kind of specialization of personal and social thinking in life, the result of implementing rule (3); this means there needs to be a two-way interplay of ideas, arguments and experiences between the social world and academia, in accordance with rule (4). This is represented, in figure 1 , by the two-way arrows linking academic inquiry and the social world. ${ }^{5}$

The natural and technological sciences need to recognize three domains of discussion: evidence, theory, and aims. Discussion of aims seeks to identify that highly problematic region of overlap between that which is discoverable, and that which it is of value to discover. Discussion of what it is of value to discover interacts with social inquiry, in accordance with rule (4).

It may be asked: but if academic inquiry today really does suffer from the wholesale structural irrationality just indicated, when and how did this come about? I turn now to a consideration of that question. The answer leads to an improved version of wisdominquiry, and to a new argument in support of my claim that wisdom-inquiry, potentially, is more rigorous and of greater human value, than knowledge-inquiry.

\section{The Traditional Enlightenment}

The irrationality of contemporary academic inquiry has its roots in blunders made by the philosophes of the 18th century Enlightenment.

A basic idea of the Enlightenment, perhaps the basic idea, was to try to learn from scientific progress how to go about making social progress towards an enlightened world. The philosophes, Voltaire, Diderot, Condorcet and others, did what they could to put this immensely important idea into practice, in their lives. They fought dictatorial power, superstition, and injustice with weapons no more lethal than those of argument and wit. They gave their support to the virtues of tolerance, openness to doubt, readiness to learn from criticism and from experience. Courageously and energetically they laboured to promote rationality in personal and social life (Gay, 1973).

Unfortunately, in developing the Enlightenment idea intellectually, the philosophes blundered. They thought the task was to develop the social sciences alongside the natural sciences. I shall call this the traditional Enlightenment Programme. It was developed throughout the 19th century, by Comte, Marx, Mill and others, and built into the institutional structure of universities during the 20th century, with the creation of departments of social science (see Aron, 1968, 1970; Farganis, 1993, Introduction; Hayek, 1979). Knowledge-inquiry, as we have it today, by and large, is the result, both natural science and social inquiry being devoted, in the first instance, to the pursuit of knowledge.

\footnotetext{
${ }^{5}$ This two-way interaction between science and society is emphasized by Nowotny et al. (2001).
} 
But, from the standpoint of creating a kind of inquiry designed to help humanity learn how to become civilized, all this amounts to a series of monumental blunders. These blunders are at the root of the damaging irrationality of current academic inquiry.

\section{The New Enlightenment}

In order to implement properly the basic Enlightenment idea of learning from scientific progress how to achieve social progress towards a civilized world, it is essential to get the following three steps right.

1. The progress-achieving methods of science need to be correctly identified.

2. These methods need to be correctly generalized so that they become fruitfully applicable to any human endeavour, whatever the aims may be, and not just applicable to the endeavour of improving knowledge.

3. The correctly generalized progress-achieving methods then need to be exploited correctly in the great human endeavour of trying to make social progress towards an enlightened, wise, civilized world.

Unfortunately, the philosophes of the Enlightenment got all three points wrong. And as a result these blunders, undetected and uncorrected, are built into the intellectualinstitutional structure of academia as it exists today. ${ }^{6}$

First, the philosophes failed to capture correctly the progress-achieving methods of natural science. From D' Alembert in the $18^{\text {th }}$ century to Popper in the $20^{\text {th }}$ (Popper, 1963), the widely held view, amongst both scientists and philosophers, has been (and continues to be) that science proceeds by assessing theories impartially in the light of evidence, no permanent assumption being accepted by science about the universe independently of evidence. But this standard empiricist view is untenable. If taken literally, it would instantly bring science to a standstill. For, given any accepted theory of physics, T, Newtonian theory say, or quantum theory, endlessly many empirically more successful rivals can be concocted which agree with $\mathrm{T}$ about observed phenomena but disagree arbitrarily about some unobserved phenomena. Physics would be drowned in an ocean of such empirically more successful rival theories.

In practice, these rivals are excluded because they are disastrously disunified. Two considerations govern acceptance of theories in physics: empirical success and unity. But in persistently accepting unified theories, to the extent of rejecting disunified rivals that are just as, or even more, empirically successful, physics makes a big persistent assumption about the universe. The universe is such that all disunified theories are false. It has some kind of unified dynamic structure. It is physically comprehensible in the sense that explanations for phenomena exist to be discovered.

But this untestable (and thus metaphysical) assumption that the universe is comprehensible is profoundly problematic. Science is obliged to assume, but does not

\footnotetext{
${ }^{6}$ The blunders of the philosophes are not entirely undetected. Karl Popper, in his first four works, makes substantial improvements to the traditional Enlightenment programme (although Popper does not himself present his work in this fashion). Popper first improves traditional conceptions of the progress-achieving methods of science (Popper, 1959). This conception, falsificationism, is then generalized to become critical rationalism. This is then applied to social, political and philosophical problems (Popper, 1961, 1962, 1963). The version of the Enlightenment programme about to be outlined here can be regarded as a radical improvement of Popper's version: see Maxwell (2004, chapter 3).
} 
know, that the universe is comprehensible. Much less does it know that the universe is comprehensible in this or that way. A glance at the history of physics reveals that ideas have changed dramatically over time. In the $17^{\text {th }}$ century there was the idea that the universe consists of corpuscles, minute billiard balls, which interact only by contact. This gave way to the idea that the universe consists of point-particles surrounded by rigid, spherically symmetrical fields of force, which in turn gave way to the idea that there is one unified self-interacting field, varying smoothly throughout space and time. Nowadays we have the idea that everything is made up of minute quantum strings embedded in ten or eleven dimensions of space-time. Some kind of assumption along these lines must be made but, given the historical record, and given that any such assumption concerns the ultimate nature of the universe, that of which we are most ignorant, it is only reasonable to conclude that it is almost bound to be false.

The way to overcome this fundamental dilemma inherent in the scientific enterprise is to construe physics as making a hierarchy of metaphysical assumptions concerning the comprehensibility and knowability of the universe, these assumptions asserting less and less as one goes up the hierarchy, and thus becoming more and more likely to be true: see figure 2. In this way a framework of relatively insubstantial, unproblematic, fixed assumptions and associated methods is created within which much more substantial and problematic assumptions and associated methods can be changed, and indeed improved, as scientific knowledge improves. Put another way, a framework of relatively unspecific, unproblematic, fixed aims and methods is created within which much more specific and problematic aims and methods evolve as scientific knowledge evolves. (A basic aim of science is to discover in what precise way the universe is comprehensible, this aim evolving as assumptions about comprehensibility evolve.) There is positive feedback between improving knowledge, and improving aims-and-methods, improving knowledge-about-how-to-improve-knowledge. This is the nub of scientific rationality, the methodological key to the unprecedented success of science. ${ }^{7}$ Science adapts its nature to what it discovers about the nature of the universe (see Maxwell, 1974, 1976, 1984, 1998, 2004, 2005).

So much for the first blunder of the traditional Enlightenment, and how to put it right.

Second, having failed to identify the methods of science correctly, the philosophes naturally failed to generalize these methods properly. They failed to appreciate that the idea of representing the problematic aims (and associated methods) of science in the form of a hierarchy can be generalized and applied fruitfully to other worthwhile enterprises besides science. Many other enterprises have problematic aims - problematic because aims conflict, and because what we seek may be unrealizable, undesirable, or both. Such enterprises, with problematic aims, would benefit from employing a hierarchical methodology, generalized from that of science, thus making it possible to improve aims and methods as the enterprise proceeds. There is the hope that, as a result of exploiting in

\footnotetext{
${ }^{7}$ Natural science has made such astonishing progress in improving knowledge and understanding of nature because it has put something like the hierarchical methodology, indicated here, into scientific practice. Officially, however, scientists continue to hold the standard empiricist view that no untestable metaphysical theses concerning the comprehensibility and knowability of the universe are accepted as a part of scientific knowledge. As I have argued elsewhere (Maxwell, 2004, chapter 2), science would be even more successful, in a number of ways, if scientists adopted and explicitly implemented the hierarchical methodology indicated here.
} 
life methods generalized from those employed with such success in science, some of the astonishing success of science might be exported into other worthwhile human endeavours, with problematic aims quite different from those of science.

Third, and most disastrously of all, the philosophes failed completely to try to apply such generalized, hierarchical progress-achieving methods to the immense, and profoundly problematic enterprise of making social progress towards an enlightened,

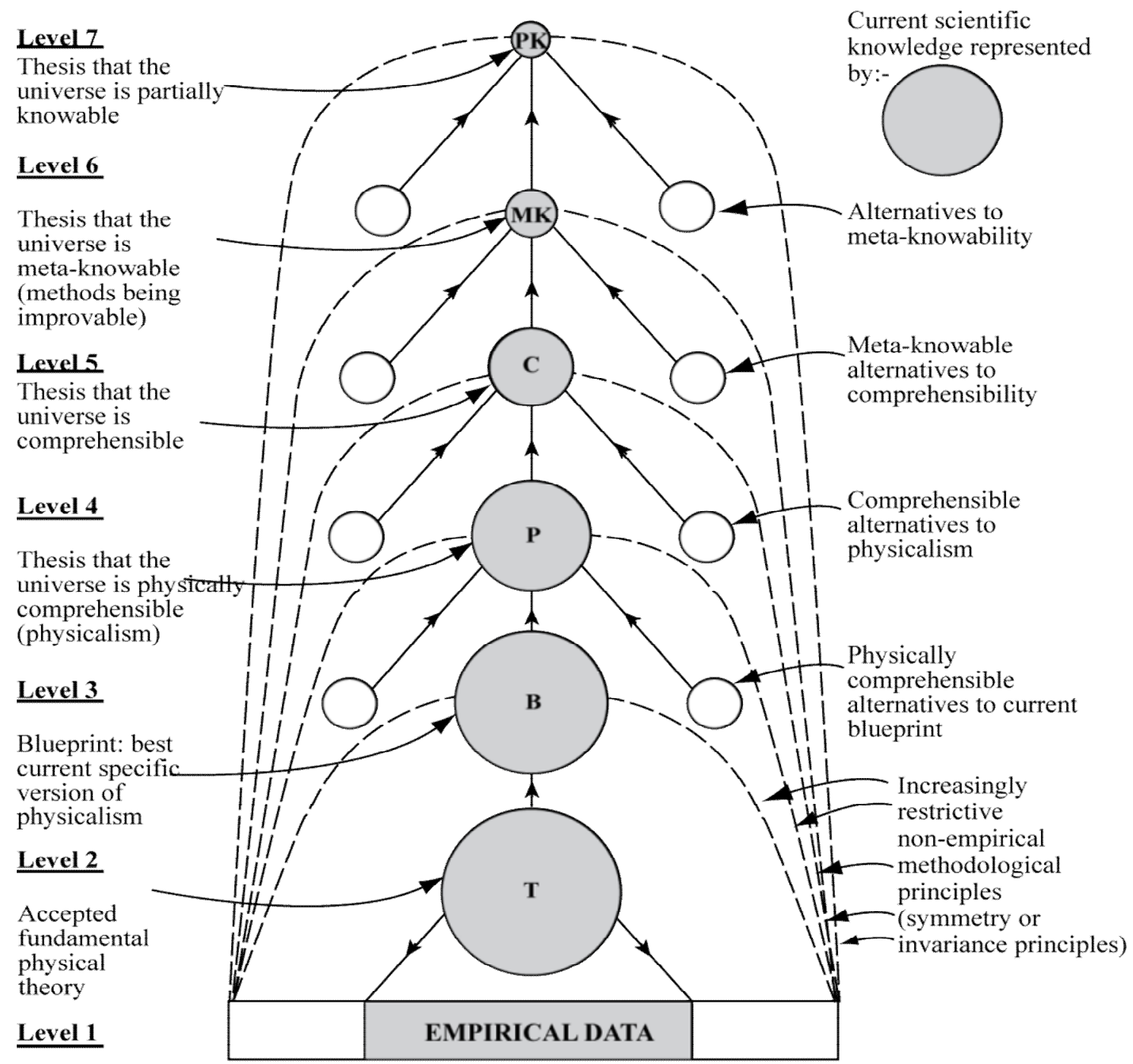

Figure 2: Hierarchical Conception of Science

wise world. The aim of such an enterprise is notoriously problematic. For all sorts of reasons, what constitutes a good world, an enlightened, wise or civilized world, attainable and genuinely desirable, must be inherently and permanently problematic. ${ }^{8}$ Here, above

\footnotetext{
${ }^{8}$ There are a number of ways of highlighting the inherently problematic character of the aim of creating civilization. People have very different ideas as to what does constitute civilization.
} 
all, it is essential to employ the generalized version of the hierarchical, progressachieving methods of science, designed specifically to facilitate progress when basic aims are problematic: see Figure 3. It is just this that the philosophes failed to do. Instead of applying the hierarchical methodology to social life, the philosophes sought to apply a seriously defective conception of scientific method to social science, to the task of making progress towards, not a better world, but to better knowledge of social phenomena. And this ancient blunder is still built into the institutional and intellectual structure of academia today, inherent in the current character of social science (Maxwell, 1984, 2007, chapters 3, 6 and 7).

Properly implemented, in short, the Enlightenment idea of learning from scientific progress how to achieve social progress towards an enlightened world would involve developing social inquiry, not as social science, but as social methodology, or social philosophy. A basic task would be to get into personal and social life, and into other institutions besides that of science - into government, industry, agriculture, commerce, the media, law, education, international relations - hierarchical, progress-achieving methods (designed to improve problematic aims) arrived at by generalizing the methods of science. A basic task for academic inquiry as a whole would be to help humanity learn how to resolve its conflicts and problems of living in more just, cooperatively rational ways than at present. This task would be intellectually more fundamental than the scientific task of acquiring knowledge. Social inquiry would be intellectually more fundamental than physics. As I have already remarked, academia would be a kind of people's civil service, doing openly for the public what actual civil services are supposed to do in secret for governments. Academia would have just sufficient power (but no more) to retain its independence from government, industry, the press, public opinion, and other centres of power and influence in the social world. It would seek to learn from, educate, and argue with the great social world beyond, but would not dictate. Academic thought would be pursued as a specialized, subordinate part of what is really important and fundamental: the thinking that goes on, individually, socially and institutionally, in the social world, guiding individual, social and institutional actions and life. The fundamental intellectual and humanitarian aim of inquiry would be to help humanity acquire wisdom - wisdom being the capacity to realize (apprehend and create) what is of

Most views about what constitutes Utopia, an ideally civilized society, have been unrealizable and profoundly undesirable. People's interests, values and ideals clash. Even values that, one may hold, ought to be a part of civilization may clash. Thus freedom and equality, even though inter-related, may nevertheless clash. It would be an odd notion of individual freedom which held that freedom was for some, and not for others; and yet if equality is pursued too singlemindedly this will undermine individual freedom, and will even undermine equality, in that a privileged class will be required to enforce equality on the rest, as in the old Soviet Union. A basic aim of legislation for civilization, we may well hold, ought to be increase freedom by restricting it: this brings out the inherently problematic, paradoxical character of the aim of achieving civilization. One thinker who has stressed the inherently problematic, contradictory character of the idea of civilization is Isaiah Berlin; see, for example, Berlin (1980, pp. 74-79). Berlin thought the problem could not be solved; I, on the contrary, hold that the hierarchical methodology indicated here provides us with the means to learn how to improve our solution to it in real life. 
value in life, for oneself and others, wisdom thus including knowledge and technological know-how but much else besides.

One outcome of getting into social and institutional life the kind of aim-evolving, hierarchical methodology indicated above, generalized from science, is that it becomes possible for us to develop and assess rival philosophies of life as a part of social life, somewhat as theories are developed and assessed within science. Such a hierarchical methodology provides a framework within which competing views about what our aims and methods in life should be - competing religious, political and moral views - may be cooperatively assessed and tested against broadly agreed, unspecific aims (high up in the hierarchy of aims) and the experience of personal and social life. There is the possibility of cooperatively and progressively improving such philosophies of life (views about what is of value in life and how it is to be achieved) much as theories are cooperatively and progressively improved in science. In science, ideally, theories are critically assessed with respect to each other, with respect to metaphysical ideas concerning the comprehensibility of the universe, and with respect to experience (observational and experimental results). In a somewhat analogous way, diverse philosophies of life may be critically assessed with respect to each other, with respect to relatively uncontroversial, agreed ideas about aims and what is of value, and with respect to experience - what we do, achieve, fail to achieve, enjoy and suffer - the aim being to improve philosophies of life (and more specific philosophies of more specific enterprises within life such as government, education or art) so that they offer greater help with the realization of what is of value in life. This hierarchical methodology is especially relevant to the task of resolving conflicts about aims and ideals, as it helps disentangle agreement (high up in the hierarchy) and disagreement (more likely to be low down in the hierarchy).

Wisdom-inquiry, because of its greater rigour, has intellectual standards that are, in important respects, different from those of knowledge-inquiry. Whereas knowledgeinquiry demands that emotions and desires, values, human ideals and aspirations, philosophies of life be excluded from the intellectual domain of inquiry, wisdom-inquiry requires that they be included. In order to discover what is of value in life it is essential that we attend to our feelings and desires. But not everything we desire is desirable, and not everything that feels good is good. Feelings, desires and values need to be subjected to critical scrutiny. And of course feelings, desires and values must not be permitted to influence judgements of factual truth and falsity. Wisdom-inquiry embodies a synthesis of traditional rationalism and romanticism. It includes elements from both, and it improves on both. It incorporates romantic ideals of integrity, having to do with motivational and emotional honesty, honesty about desires and aims; and at the same time it incorporates traditional rationalist ideals of integrity, having to do with respect for objective fact, knowledge, and valid argument. Traditional rationalism takes its inspiration from science and method; romanticism takes its inspiration from art, from imagination, and from passion. Wisdom-inquiry holds art to have a fundamental rational role in inquiry, in revealing what is of value, and unmasking false values; but science, too, is of fundamental importance. What we need, for wisdom, is an interplay of sceptical rationality and emotion, an interplay of mind and heart, so that we may develop mindful hearts and heartfelt minds. It is time we healed the great rift in our culture, so graphically depicted by Snow (1986). 
All in all, if the Enlightenment revolution had been carried through properly, the three steps indicated above being correctly implemented, the outcome would have been a kind of academic inquiry very different from what we have at present, inquiry devoted primarily to the intellectual aim of acquiring knowledge.

\section{Cultural Implications of Wisdom-Inquiry}

Wisdom-inquiry does not just do better justice to the social or practical dimension of inquiry than knowledge-inquiry; it does better justice to the "intellectual" or "cultural" aspects as well.

From the standpoint of the intellectual or cultural aspect of inquiry, what really matters is the desire that people have to see, to know, to understand, the passionate curiosity that individuals have about aspects of the world, and the knowledge and understanding that people acquire and share as a result of actively following up their

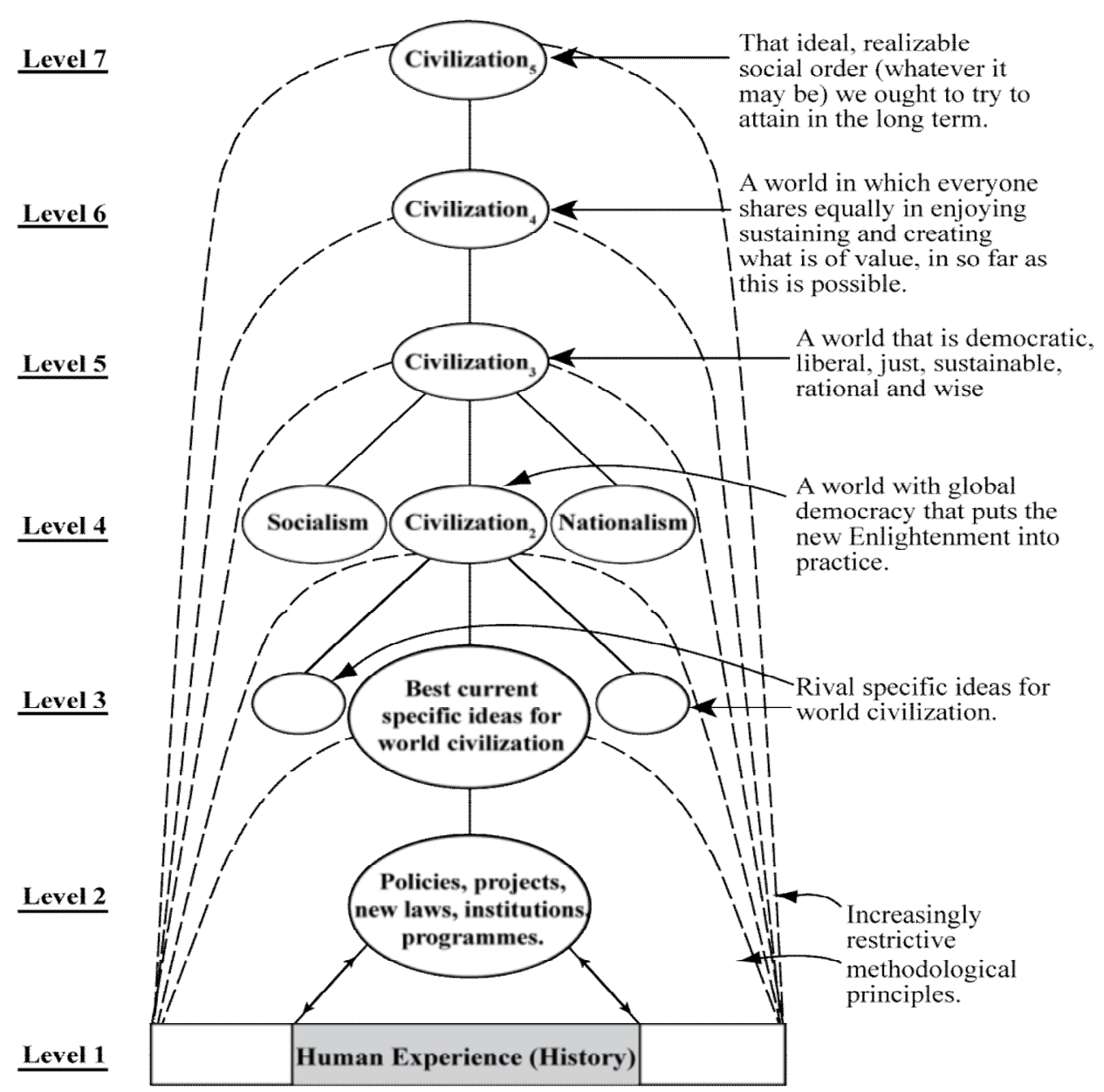

Figure 3: Hierarchical Social Methodology Generalized from Science

curiosity. An important task for academic thought in universities is to encourage nonprofessional thought to flourish outside universities. As Einstein once remarked 
"Knowledge exists in two forms - lifeless, stored in books, and alive in the consciousness of men. The second form of existence is after all the essential one; the first, indispensable as it may be, occupies only an inferior position." (Einstein, 1973, p. 80).

Wisdom-inquiry is designed to promote all this in a number of ways. It does so as a result of holding thought, at its most fundamental, to be the personal thinking we engage in as we live. It does so by recognizing that acquiring knowledge and understanding involves articulating and solving personal problems that one encounters in seeking to know and understand. It does so by recognizing that passion, emotion and desire, have a rational role to play in inquiry, disinterested research being a myth. Again, as Einstein has put it "The most beautiful experience we can have is the mysterious. It is the fundamental emotion which stands at the cradle of true art and true science. Whoever does not know it and can no longer wonder, no longer marvel, is as good as dead, and his eyes are dimmed." (Einstein, 1973, p. 11).

Knowledge-inquiry, by contrast, all too often fails to nourish "the holy curiosity of inquiry" (Einstein, 1949, p. 17), and may even crush it out altogether. Knowledgeinquiry gives no rational role to emotion and desire; passionate curiosity, a sense of mystery, of wonder, have no place, officially, within the rational pursuit of knowledge. The intellectual domain becomes impersonal and split off from personal feelings and desires; it is difficult for "holy curiosity" to flourish in such circumstances. Knowledgeinquiry hardly encourages the view that inquiry at its most fundamental is the thinking that goes on as a part of life; on the contrary, it upholds the idea that fundamental research is highly esoteric, conducted by physicists in contexts remote from ordinary life. Even though the aim of inquiry may, officially, be human knowledge, the personal and social dimension of this is all too easily lost sight of, and progress in knowledge is conceived of in impersonal terms, stored lifelessly in books and journals. Rare is it for popular books on science to take seriously the task of exploring the fundamental problems of a science in as accessible, non-technical and intellectually responsible a way as possible. ${ }^{9}$ Such work is not highly regarded by knowledge-inquiry, as it does not contribute to "expert knowledge". The failure of knowledge-inquiry to take seriously the highly problematic nature of the aims of inquiry leads to insensitivity as to what aims are being pursued, to a kind of institutional hypocrisy. Officially, knowledge is being sought "for its own sake", but actually the goal may be immortality, fame, the flourishing of one's career or research group, as the existence of bitter priority disputes in science indicates. Education suffers. Science students are taught a mass of established scientific knowledge, but may not be informed of the problems which gave rise to this knowledge, the problems which scientists grappled with in creating the knowledge. Even more rarely are students encouraged themselves to grapple with such problems. And rare, too, is it for students to be encouraged to articulate their own problems of understanding that must, inevitably arise in absorbing all this information, or to articulate their instinctive criticisms of the received body of knowledge. All this tends to reduce education to a kind of intellectual indoctrination, and serves to kill "holy curiosity". ${ }^{10}$ Officially, courses in universities divide up into those that are vocational, like engineering, medicine and law,

\footnotetext{
${ }^{9}$ A recent, remarkable exception is Penrose (2004).

${ }^{10} \mathrm{I}$ might add that the hierarchical conception of science indicated here does better justice to the scientific quest for understanding than does orthodox standard empiricist views: see Maxwell (1998, chapters 4 and 8; 2004, chapter 2).
} 
and those that are purely educational, like physics, philosophy or history. What is not noticed, again through insensitivity to problematic aims, is that the supposedly purely educational are actually vocational as well: the student is being trained to be an academic physicist, philosopher or historian, even though only a minute percentage of the students will go on to become academics. Real education, which must be open-ended, and without any pre-determined goal, rarely exists in universities, and yet few notice. (These considerations are developed further in Maxwell, 1976, 1984 and 2004.)

In order to enhance our understanding of persons as beings of value, potentially and actually, we need to understand them empathetically, by putting ourselves imaginatively into their shoes, and experiencing, in imagination, what they feel, think, desire, fear, plan, see, love and hate. For wisdom-inquiry, this kind of empathic understanding is rational and intellectually fundamental. Articulating problems of living, and proposing and assessing possible solutions is, we have seen, the fundamental intellectual activity of wisdom-inquiry. But it is just this that we need to do to acquire empathic understanding. Social inquiry, in tackling problems of living, is also promoting empathic understanding of people. Empathic understanding is essential to wisdom. Elsewhere I have argued, indeed, that empathic understanding plays an essential role in the evolution of consciousness. It is required for cooperative action, and even for science. (For a fuller exposition of such an account of empathic understanding see Maxwell, 1984, pp. 171-189 and chapter 10; and 2001, chapters 5-7 and 9).

Granted knowledge-inquiry, on the other hand, empathic understanding hardly satisfies basic requirements for being an intellectually legitimate kind of explanation and understanding (Maxwell, 1984, pp. 183-185). It has the status merely of "folk psychology", on a par with "folk physics".

\section{Conclusion}

Humanity is in deep trouble. We urgently need to learn how to make progress towards a wiser, more civilized world. This in turn requires that we possess traditions and institutions of learning rationally designed - well designed - to help us achieve this end. It is just this that we do not have at present. What we have instead is natural science and, more broadly, inquiry devoted to acquiring knowledge. Judged from the standpoint of helping us create a better world, knowledge-inquiry of this type is dangerously and damagingly irrational. We need to bring about a major intellectual and institutional revolution in the aims and methods of inquiry, from knowledge-inquiry to wisdominquiry. Almost every branch and aspect of academic inquiry needs to change.

A basic intellectual task of academic inquiry would be to articulate our problems of living (personal, social and global) and propose and critically assess possible solutions, possible actions. This would be the task of social inquiry and the humanities. Tackling problems of knowledge would be secondary. Social inquiry would be at the heart of the academic enterprise, intellectually more fundamental than natural science. On a rather more long-term basis, social inquiry would be concerned to help humanity build hierarchical methods of problem-solving into the fabric of social and political life so that we may gradually acquire the capacity to resolve our conflicts and problems of living in more cooperatively rational ways than at present. Natural science would change to include three domains of discussion: evidence, theory, and aims - the latter including 
discussion of metaphysics, values and politics. Academia would actively seek to educate the public by means of discussion and debate, and would not just study the public.

This revolution - intellectual, institutional and cultural - if it ever comes about, would be comparable in its long-term impact to that of the Renaissance, the scientific revolution, or the Enlightenment. The outcome would be traditions and institutions of learning rationally designed to help us acquire wisdom. There are a few scattered signs that this intellectual revolution, from knowledge to wisdom, is already under way. It will need, however, much wider cooperative support - from scientists, scholars, students, research councils, university administrators, vice chancellors, teachers, the media and the general public - if it is to become anything more than what it is at present, a fragmentary and often impotent movement of protest and opposition, often at odds with itself, exercising little influence on the main body of academic work. I can hardly imagine any more important work for anyone associated with academia than, in teaching, learning and research, to help promote this revolution.

\section{References}

Appleyard, B., 1992, Understanding the Present: Science and the Soul of Modern Man, Picador, London.

Aron, R. 1968, Main Currents in Sociological Thought, Penguin, Harmondsworth, vol. 1 1968; vol. 2, 1970.

Berlin, I., 1980, Against the Current, Hogarth Press, London.

Berman, B., 1981, The Reenchantment of the World, Cornell University Press, Ithaca.

Einstein, A., 1949, "Autobiographical Notes", in P. A. Schilpp, ed. Albert Einstein:

Philosopher-Scientist, Open Court, Illinois, pp. 3-94. 1973, Ideas and Opinions, Souvenir Press, London.

Farganis, J. (ed.), 1993, Readings in Social Theory: The classic Tradition to PostModernism, McGraw-Hill, New York.

Feyerabend, P., 1978, Against Method, Verso, London. , 1987, Farewell to Reason, Verso, London.

Gay, P., 1973, The Enlightenment: An Interpretation, Wildwood House, London.

Hayek, F. A., 1979, The Counter-Revolution of Science, 1979, LibertyPress, Indianapolis.

Laing, R. D., 1965, The Divided Self, 1965, Penguin, Harmondsworth.

Langley, C., 2005, Soldiers in the Laboratory, Scientists for Global Responsibility, Folkstone.

Marcuse, H., 1964, One Dimensional Man, Beacon Press, Boston.

Maxwell, N., 1974, 'The Rationality of Scientific Discovery', Philosophy of Science 41, 1974, pp. 123-53 and 247-95. , 1976, What's Wrong With Science?, Bran's Head Books, Frome, England. 1980, 'Science, Reason, Knowledge and Wisdom: A Critique of Specialism', Inquiry 23, pp. 19-81. ,1984, From Knowledge to Wisdom, Blackwell, Oxford (2nd edition, enlarged,

2007, Earthscan, London). 1998, The Comprehensibility of the Universe (Oxford University Press,

Oxford, pbk. 2003). 2001, The Human World in the Physical Universe, Rowman and 
Littlefield, Lanham, Maryland. 2004, Is Science Neurotic?, Imperial College Press, London. ,2005, 'Popper, Kuhn, Lakatos and Aim-Oriented Empiricism', Philosophia 32, pp. 181-239.

Nowotny, H., Scott, P. and Gibbons, M., 2001, Re-Thinking Science, Polity Press, Cambridge.

Penrose, R., 2004, The Road to Reality, Jonathan Cape, London.

Popper, K. R., 1959, The Logic of Scientific Discovery, Hutchinson, London. , 1961, The Poverty of Historicism, Routledge and Kegan Paul, London. , 1962, The Open Society and Its Enemies, Routledge and Kegan Paul, London. 1963, Conjectures and Refutations, Routledge and Kegan Paul, London.

Roszak, T., 1973, Where the Wasteland Ends, 1973, Faber and Faber, London. Schwartz, B., 1987, The Battle for Human Nature, W. W. Norton, New York.

Smith, D., 2003, The Atlas of War and Peace, Earthscan, London.

Snow, C. P., 1986, The Two Cultures: And a Second Look, Cambridge University Press, Cambridge. 